\title{
An Evaluation Model for the Cultivation and Improvement of the Innovation Ability of College Students
}

\author{
https://doi.org/10.3991/ijet.v15i17.16735 \\ Kechuang Wang \\ Zhejiang Dongfang Polytechnic, Wenzhou, China \\ Chuankui Yan $(\varpi)$ \\ Wenzhou University, Wenzhou, China \\ yanchuankui@163.com
}

\begin{abstract}
In modern times, the innovation ability of college students is a focus of college education. However, the cultivation and improvement of this ability are constrained by many factors, and the ability is too complex to be evaluated accurately. To solve the problems, this paper puts forward an extension model suitable for evaluating the cultivation and improvement of the said ability. Firstly, the research problem was defined clearly as the evaluation of the cultivation and improvement for the innovation ability of college students. Based on the extension theory, an evaluation model was established for the cultivation and improvement of the said ability, the workflow of model implementation was explained, and the corresponding evaluation algorithm was designed in details. Finally, the proposed model and algorithm were proved operable through case analysis. The research results provide support to the solution of complex systematic decision-making problems.
\end{abstract}

Keywords-College students, innovation ability, extension decision-making, evaluation model.

\section{$1 \quad$ Introduction}

Innovation is a major development trend of modern society, and also a basic guarantee for a country or an enterprise to maintain sustained competitiveness. Therefore, it has attracted more and more researchers' attention and rapidly developed in various engineering fields [1-4]. The development of innovation is inseparable from the cultivation of senior talents, and the innovation ability of senior talents is a key feature for the effective implementation of higher education, which requires the higher education to use more innovation elements with the rapid development of scientific and technology in the 21 st century $[5,6]$. As an important aspect of the comprehensive quality, the innovation ability of college students is also a key link to improve their comprehensive quality. As a result, in the continuous reforming, more and more colleges have begun to focus on the cultivation and improvement of innovation ability of col- 
lege students, which has gradually become a hot issue in higher education research. For example, Jackson [7] analyzed the problem of competence management in the innovation reform of higher education. Gao and Zhang [8] discussed how to cultivate college students' innovation ability. Zong et al. [9] established an evaluation index system for college students' innovation quality. Li et al. [10] analyzed the model construction and development strategy of college students' innovation ability system. However, the above studies are more focused on the evaluation system, evaluation strategy analysis, and implementation of evaluation methods for the cultivation and improvement of college students' innovation ability, lacking a systematic analysis for quantitative evaluation of the said ability. So, it needs more in-depth discussion and analysis on how to effectively evaluate the effects of the cultivation and improvement, find out the weak links based on the evaluation results, and make targeted improvement. Considering that the evaluation for the cultivation and improvement of college students' innovation ability is a complex systematic project, it will involve the comprehensive effect of many factors, and there is also some uncertain information to be handled. Traditional system engineering analysis methods, such as neural networks and genetic algorithms etc., have been well applied in the field of nonlinear engineering $[11,12]$. Zagrebina et al. [13] predicted and analyzed power consumption based on recurrent neural network models. Scarselli et al. [14] analyzed the VapnikChervonenkis dimension of the graph and the recurrent neural network. Tseng et al. [15] studied the use of the block-based genetic algorithm in disassembly sequence planning. Verotti et al. [16] analyzed the numerical simulation method for the mechanical characteristics of biological samples of MEMS micro-holders based on genetic algorithm. But these analysis methods often need the support of data samples, and are difficult to deal with fuzzy information. Fuzzy system and gray system theory can deal with fuzzy information, and have a wide range of applications in the field of engineering, e.g., Bezuglov and Comert [17] studied the prediction of traffic parameters in intelligent transportation systems based on gray theory; Lee et al. [18] analyzed the optimal design of the alignment platform through gray correlation analysis; de Gusmão et al. [19] discussed about the network security risk analysis models based on fault tree analysis and fuzzy decision theory; Shariat et al. [20] conducted a risk analysis of urban rainwater infrastructure system using the fuzzy spatial multi-criteria decision-making. Nevertheless, the connotation and extension of these said method in dealing with fuzzy information are often not complete. Extenics is a trans-disciplinary subject that uses formal models to study the possibility of extending things and innovates the rules and methods to solve contradictory problems. It has a wide range of applications in the field of engineering [21-23]. As above, this paper attempts to realize the effective evaluation for the cultivation and improvement effect of college students' innovation ability. Based on extension theory, it uses extension decisionmaking and evaluation method [24-26] to explore the cultivation and improvement of innovation ability of college students. It's expected to provide support for complex systematic decision-making problems.

The remainder of this paper is organized as follows: Section 2 defines the essential issues for the evaluation of the cultivation and improvement of college students' innovation ability; Section 3 analyses the evaluation indicators for the cultivation and 
improvement of the said ability, including the selection principles of evaluation indicators, the software strength and hardware configuration of college students' innovation, the individual factors of college students, and the achievements etc.; Section 4 establishes the evaluation model and algorithm based on extension theory; Section 5 verifies the established extension evaluation model and algorithm through case analysis; Section 6 gives the conclusions.

\section{Essential Issues for the Evaluation of the Cultivation and Improvement of College Students' Innovation Ability}

The evaluation for the cultivation and improvement of innovation ability of college students is essentially to measure its implementation effect. As the main carrier for the innovation, college students are naturally the most direct manifestation of the evaluation effectiveness. The effectiveness is also embodied in other carriers such as intellectual level, technological quality, innovation environment, innovation awareness, innovation achievement, technological competitiveness, social service, and influence, etc. However, these carriers are restricted by many factors, which should be considered in the evaluation for the cultivation and improvement of college students' innovation ability. From a narrow perspective, the college students' innovation ability is cultivated and improved mainly in terms of teaching and learning; the teaching is limited by the hardware and software conditions of colleges, while the learning is affected by the comprehensive quality of college students. Therefore, the evaluation for the cultivation and improvement of the said ability is mainly reflected in the four aspects: hardware configuration, software strength, college students' individual factors, and achievements. Their hierarchical structure relationship is shown in Figure 1.

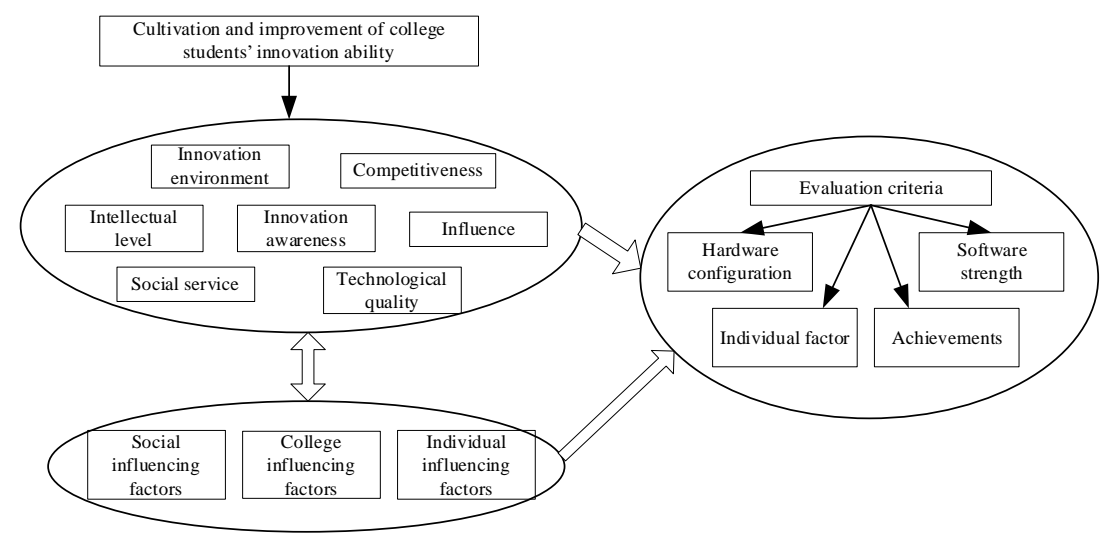

Fig. 1. Hierarchical structure relationship 


\section{Analysis on Evaluation Indicators of Cultivation and Improvement of College Students' Innovation Ability}

\subsection{Basic selection principles of evaluation indicators}

Principle of scientific: The selected evaluation indicators can scientifically and reasonably reflect the essential problems in the cultivation and promotion of college students' innovation ability.

Principle of pertinence: it's necessary to combine the training planning goals of the said ability, and select the representative evaluation indicators in a targeted manner, that is, the typical characteristics of the cultivation and improvement of college students' innovation ability should be analyzed and evaluated.

Principle of objectivity: the selection of indicators should be combined with the actual situation of the college students' innovation ability training program, reflecting the related objective factors, and avoiding the subjective factors.

Principle of operability: the selected evaluation indicators should be convenient for quantitative analysis of the cultivation and improvement of the said ability; the qualitative evaluation index can be easily converted into a quantitative description, and the fuzzy evaluation index can be easily into an accurate description.

\subsection{College students' innovation hardware configuration}

Hardware configuration is the basic carrier and platform for the cultivation and improvement of college students' innovation ability. The good condition of hardware configuration is a catalyst for improving the college students' innovation ability. Its evaluation indicators are mainly reflected in: construction of college students' innovation center (platform), construction of social practice center (platform), implementation of industry-university-research mode, innovation hardware facilities, innovation venues (incl. laboratories) construction, innovation management institution construction, innovation system construction, innovation incentive mechanism, and innovation echelon construction etc.

\subsection{College students' innovation software strength}

Software strength is an important part of the cultivation and improvement of college students' innovation ability. The solid software strength is an important guarantee for colleges to effectively cultivate and improve the innovation ability of college students. Its evaluation indicators are mainly reflected in: innovation fund setting of college students, innovation capital investment, innovation instructor strength, innovation research and teaching team construction, innovation design curriculum construction, teaching mode and content, classroom and practical teaching effect, innovation community construction, activity organization, innovation competitions, and the innovation promotion etc. 


\subsection{Individual factors of college students}

The individual factor is the individual performance for the cultivation and improvement of college students' innovation ability. Different individuals may vary in the adaptability, and the training characteristics of individuals are also different. Therefore, the effective extraction of key factors affecting the cultivation and improvement is very conductive to analyzing college students' innovation quality. Its evaluation indicators are mainly reflected in: innovative learning ability, innovative awareness, innovative thinking ability, innovative design ability, social practice ability, teamwork (collaboration) ability, basic knowledge reserve, professional knowledge reserve, communication ability, innovation participation, and innovation awareness, etc.

\subsection{Achievements of cultivation}

Achievements are the most intuitive reflection of the cultivation and improvement effect on college students' innovation ability, and the related evaluation objectives are also more targeted. Its evaluation indicators are mainly reflected in: social competitiveness, social service awareness, awards for innovation activities and competitions, innovation papers, innovation patents, innovation projects, innovation reports, innovation works, participation in scientific research projects, participation in competitions and activities, qualification rate of innovation training, excellent rate of innovation training, transformation rate of the innovation achievements, and the reform of innovation teaching.

\section{Establishment of an Evaluation Model for the Cultivation and Improvement of College Students' Innovation Abilities Based on Extension Theory}

\subsection{Modeling of matter-element model}

Assuming that the object to be evaluated has $n$ evaluation characteristics for cultivation and improvement of the college students' innovation ability, the $i$-th characteristic is recorded as $c_{i}$, and the corresponding characteristic value is recorded as $v\left(c_{i}\right)$, then the matter-element model of the evaluation object is expressed as $R$ :

$$
R=\left[\begin{array}{ccc}
\Gamma(R) & c_{1} & V\left(c_{1}\right) \\
& c_{2} & V\left(c_{2}\right) \\
\vdots & \vdots \\
& c_{n} & V\left(c_{n}\right)
\end{array}\right]
$$

where, $\Gamma(\mathrm{R})$ is the name of the matter-element model R. 


\subsection{AHP-based matter-element feature weighting}

Considering that different evaluation characteristics often have different effects on the evaluation results, they need to be weighted accordingly. In this paper, the AHP method $[25,26]$ was used to assign the weights.

First, divide the target layer, criterion layer and index layer of the object to be evaluated.

Secondly, establish a judgment matrix $A$ of matter-element features according to the expert evaluation.

$$
A=\left(a_{i j}\right)_{m x m}=\left[\begin{array}{cccc}
a_{11} & a_{12} & \cdots & a_{1 n} \\
a_{21} & a_{22} & \cdots & a_{2 n} \\
\cdots & \cdots & \cdots & \cdots \\
a_{n 1} & a_{n 2} & \cdots & a_{n n}
\end{array}\right]
$$

where, aij represents the weight comparison between two matter-element features, which was determined by 1-9 scale method, as shown in Table 1.

Table 1. 1-9 scale method

\begin{tabular}{|c|l|}
\hline $\boldsymbol{a}_{i j}$ scale & \multicolumn{1}{c|}{$\boldsymbol{a}_{i j}$ definition } \\
\hline 1 & $i$ is as important as $j$ \\
\hline 3 & $i$ is slightly more important than $j$ \\
\hline 5 & $i$ is significantly more important than $j$ \\
\hline 7 & $i$ is much more important than $j$ \\
\hline 9 & $i$ is extremely more important than $j$ \\
\hline $2,4,6,8$ & Between the above adjacent connotations \\
\hline$a_{i j}$ & $a_{i j}=1 / a_{i j}$ \\
\hline
\end{tabular}

Afterwards, the weight was calculated according to the judgment matrix $A$.

$$
w_{i}=\frac{1}{m} \sum_{j=1}^{m}\left(a_{i j} / \sum_{i=1}^{m} a_{i j}\right)
$$

Besides, other weight calculation models like formula (3) can also be used for calculation according to the actual situation.

Finally, conduct a consistency check.

$$
\begin{gathered}
C I=\frac{\lambda_{\max }-m}{m-1} \\
C R=\frac{C I}{R I}
\end{gathered}
$$


The value of RI can be checked from the RI table. If satisfying $\mathrm{CR} \leq 0.1$, it indicates that the weight of matter-element features is reasonable, otherwise the judgment matrix needs to be readjusted for calculation and analysis.

\subsection{Screening of extension decision-making conditions}

In the process of evaluating the cultivation and improvement of college students' innovation ability based on extension theory, some extension evaluation conditions must be met by the objects to be evaluated, so that they can be qualified for subsequent evaluation and analysis. These conditions are called the main conditions, while the others are generally called basic conditions. Both types of conditions are the extension decision-making conditions for college students to develop and improve their innovation ability. But the extension decision-making conditions can be evaluated and analyzed, only when the main conditions are met.

\subsection{Division of the classical domain}

Assuming that all indicators are positive indicators after standardization, the evaluation levels were divided according to the actual evaluation needs of college students' innovation ability. If it's divided into $h$ evaluation levels, then the classical domain of the $i$-th matter-element feature at the $k$-th level is expressed as $V^{k}\left(c_{i}\right)=$ $\left[v_{a}^{k}\left(c_{i}\right), v_{b}^{k}\left(c_{i}\right)\right], v_{a}^{k}\left(c_{i}\right) \leq v_{b}^{k}\left(c_{i}\right)$, and the joint domain is expressed as $V^{*}\left(c_{i}\right)=$ $\left[v_{a}^{*}\left(c_{i}\right), v_{b}^{*}\left(c_{i}\right)\right], v_{a}^{*}\left(c_{i}\right) \leq v_{b}^{*}\left(c_{i}\right)$. Thus, the matter-element of classical domain at the $k$ level is given as $R_{k}$ :

$$
R_{k}=\left[\begin{array}{ccc}
\Gamma\left(R_{k}\right) & c_{1} & {\left[v_{a}^{k}\left(c_{1}\right), v_{b}^{k}\left(c_{1}\right)\right]} \\
& c_{2} & {\left[v_{a}^{k}\left(c_{2}\right), v_{b}^{k}\left(c_{2}\right)\right]} \\
\vdots & \vdots \\
& c_{n} & {\left[v_{a}^{k}\left(c_{n}\right), v_{b}^{k}\left(c_{n}\right)\right]}
\end{array}\right]
$$

The joint domain matter-element is expressed as:

$$
R^{*}=\left[\begin{array}{ccc}
\Gamma\left(R^{*}\right) & c_{1} & {\left[v_{a}^{*}\left(c_{1}\right), v_{b}^{*}\left(c_{1}\right)\right]} \\
& c_{2} & {\left[v_{a}^{*}\left(c_{2}\right), v_{b}^{*}\left(c_{2}\right)\right]} \\
\vdots & \vdots \\
& c_{n} & {\left[v_{a}^{*}\left(c_{n}\right), v_{b}^{*}\left(c_{n}\right)\right]}
\end{array}\right]
$$




\subsection{Calculation of extension correlation}

It's assumed that the matter-element of the object to be evaluated for the cultivation and improvement of college students' innovation ability is $R_{p}$ :

$$
R_{p}=\left[\begin{array}{ccc}
\Gamma\left(R_{p}\right) & c_{1} & {\left[v_{a}^{p}\left(c_{1}\right), v_{b}^{p}\left(c_{1}\right)\right]} \\
& c_{2} & {\left[v_{a}^{p}\left(c_{2}\right), v_{b}^{p}\left(c_{2}\right)\right]} \\
\vdots & \vdots \\
& c_{n} & {\left[v_{a}^{p}\left(c_{n}\right), v_{b}^{p}\left(c_{n}\right)\right]}
\end{array}\right]
$$

When a certain feature of the object to be evaluated can accurately obtain evaluation data, the, the corresponding feature value is an accurate value.

In this paper, the classical extension distance calculation model was used for analysis. For the matter-element feature ci, the extension distance between Rp and Rk is expressed as pik:

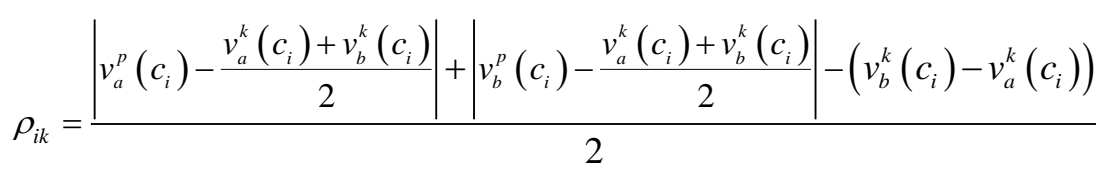

The extension distance between Rp and $\mathrm{R}^{*}$ is expressed as $\rho_{i k}^{*}$ :

$\rho_{i k}^{*}=\frac{\left|v_{a}^{p}\left(c_{i}\right)-\frac{v_{a}^{*}\left(c_{i}\right)+v_{b}^{*}\left(c_{i}\right)}{2}\right|+\left|v_{b}^{p}\left(c_{i}\right)-\frac{v_{a}^{*}\left(c_{i}\right)+v_{b}^{*}\left(c_{i}\right) \mid}{2}\right|-\left(v_{b}^{*}\left(c_{i}\right)-v_{a}^{*}\left(c_{i}\right)\right)}{2}$

It should be noted that the adopted extension distances may vary under different extension evaluation situations, and they need to be established in combination with the actual evaluation type.

Similarly, for matter-element feature ci, the extension correlation coefficient between $\mathrm{Rp}$ and $\mathrm{Rk}$ is expressed as $\eta \mathrm{ik}$ :

$$
\eta_{i k}=\left\{\begin{array}{lc}
-\rho_{i k} /\left|V^{p}\left(c_{i}\right)\right|, & V^{p}\left(c_{i}\right) \in V^{k}\left(c_{i}\right) \\
\rho_{i k} /\left(\rho_{i k}^{*}-\rho_{i k}\right), & V^{p}\left(c_{i}\right) \notin V^{k}\left(c_{i}\right)
\end{array}\right.
$$

Considering the feature weight of matter-element, the extension correlation between $\mathrm{Rp}$ and $\mathrm{Rk}$ is expressed as $\mathrm{Kk}$ : 


$$
K_{k}=\sum_{j=1}^{m}\left(w_{i} \times \eta_{i k}\right)
$$

The extension decision-making principles for evaluating the cultivation and improvement of college students' innovation ability are:

$$
K_{p}=K_{k}=\max _{1 \leq k \leq m}\left\{K_{k}\right\}
$$

That is, if satisfying formula (13), it indicates that the extension evaluation level of the object to be evaluated is $\mathrm{k}$.

\subsection{Extension evaluation model and algorithm}

Based on the above analysis, the implementation of the extension evaluation model for the cultivation and improvement of college students' innovation ability mainly includes three main components, namely, selection of extension evaluation indicators, preliminary screening based on main conditions, and calculation analysis of extension evaluation. Figure 2 shows the specific implementation workflow of the extension evaluation model and algorithm for the cultivation and improvement of college students' innovation ability.

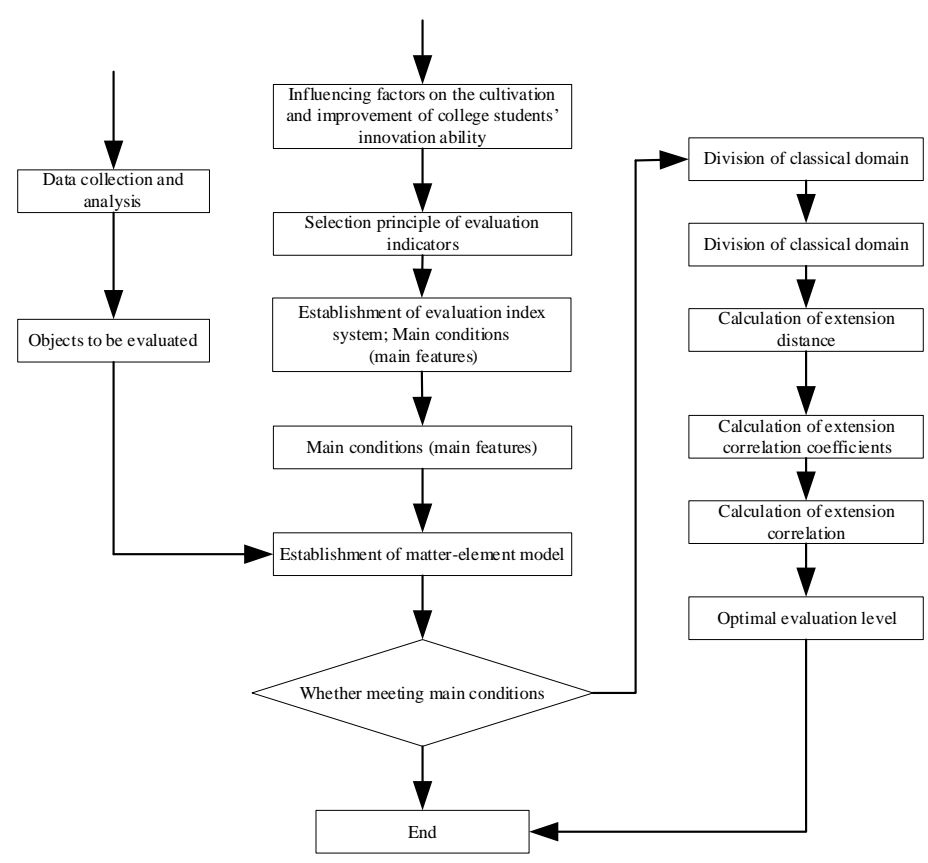

Fig. 2. Implementation workflow of evaluation model and algorithm 


\section{$5 \quad$ Case Analysis}

Taking the evaluation of some college students' innovation ability as an example, the authors described the workflow to realize the extension evaluation model for the cultivation and improvement of college students' innovation ability. For convenience of understanding, this paper only selects college students' individual factors and the achievements of cultivation for evaluation: the former focuses on the examination of innovation ability, and the latter emphasizes the direct innovation results. For this reason, an extension evaluation system was formed, as shown in Table 2.

Table 2. Extension evaluation system

\begin{tabular}{|c|c|c|}
\hline System & First level indicator & Second level indicator \\
\hline \multirow{10}{*}{ Extension evaluation system $S$} & \multirow{6}{*}{ Individual factor $S_{I}$} & Innovative consciousness $s_{11}$ \\
\hline & & Innovative thinking $s_{12}$ \\
\hline & & Innovative design capabilities $s_{13}$ \\
\hline & & Innovative learning ability $s_{14}$ \\
\hline & & Basic knowledge reserve $s_{15}$ \\
\hline & & Professional knowledge reserve $s_{16}$ \\
\hline & \multirow{4}{*}{ Achievements of cultivation $S_{2}$} & Participation in competitions and events $s_{21}$ \\
\hline & & Participation in research projects $s_{22}$ \\
\hline & & Number of competition awards $s_{23}$ \\
\hline & & Number of papers and patents $s_{24}$ \\
\hline
\end{tabular}

Based on AHP, the weight judgment matrix A1 and A2 of the first-level indicators and the second-level indicators were established, namely,

$$
A_{1}=\left[\begin{array}{llllll}
1 & \frac{1}{2} & \frac{1}{3} & \frac{1}{3} & \frac{1}{2} & \frac{1}{3} \\
2 & 1 & \frac{2}{3} & 1 & 2 & \frac{1}{2} \\
3 & \frac{3}{2} & 1 & 2 & 3 & 1 \\
3 & 1 & \frac{1}{2} & 1 & 2 & \frac{2}{3} \\
2 & \frac{1}{2} & \frac{1}{3} & \frac{1}{2} & 1 & \frac{1}{2} \\
3 & 2 & 1 & \frac{3}{2} & 2 & 1
\end{array}\right], \quad A_{2}=\left[\begin{array}{cc}
1 & 2 \\
\frac{1}{2} & 1
\end{array}\right], \quad\left[\begin{array}{cccc}
1 & 2 & 3 & 5 \\
\frac{1}{2} & 1 & 2 & 3 \\
\frac{1}{3} & \frac{1}{2} & 1 & 2 \\
\frac{1}{5} & \frac{1}{3} & \frac{1}{2} & 1
\end{array}\right]
$$

After performing the consistency check, the corresponding feature weights are obtained as 


$$
\begin{aligned}
& W=\left\{w_{1}, w_{2}\right\}=\{0.667,0.0333\} \\
& W_{1}=\left\{w_{11}, w_{12}, w_{13}, w_{14}, w_{15}\right\}=\{0.069,0.158,0.261,0.169,0.100,0.243\} \\
& W_{2}=\left\{w_{21}, w_{22}, w_{23}, w_{24}\right\}=\{0.483,0.272,0.157,0.088\}
\end{aligned}
$$

In this section, the participation in competitions and activities and research projects were selected as the main decision-making conditions, that is, college students are eligible to participate in the evaluation only after participating in certain competitions and activities or research projects, otherwise, the evaluation shall fail. In general, the evaluation is divided into four levels: excellent, good, qualified and disqualified, and the corresponding classical domains are [0.9, 1.0], [0.8, 0.9], [0.6, 0.8], and [0, 0.6] respectively. It needs to be noted that the classical domains at different levels corresponding to different matter-element features are not necessarily the same, and can be flexibly adjusted according to the actual evaluation situation. For the convenience of expression, all matter-element features were assumed to be normalized indicators in this paper.

If the matter-element model of the object to be evaluated is:

$$
R_{p}=\left[\begin{array}{l}
R_{p 1} \\
R_{p 2}
\end{array}\right]=\left[\begin{array}{ccc}
\Gamma\left(R_{p 1}\right) & s_{11} & 0.80 \\
& s_{12} & 0.60 \\
& s_{13} & 0.80 \\
& s_{14} & 0.60 \\
& s_{15} & 0.95 \\
s_{16} & 0.95
\end{array}\right] \cup\left[\begin{array}{lll}
\Gamma\left(R_{p 2}\right) & s_{21} & 0.90 \\
& s_{22} & 0.90 \\
& s_{23} & 0.80 \\
& s_{24} & 0.60
\end{array}\right]
$$

Using the classic extension correlation calculation model, the extension correlations corresponding to the four evaluation levels were $-0.083,-0.197,-0.748$, and 1.065 , which shows that the evaluation level of the selected college students was at the excellent level. This case was given just to illustrate the implementation workflow of the model and algorithm. In the process of specific application, it is necessary to adjust the matter-element features, feature weights, classical domains, and feature values according to the actual situation.

\section{Conclusion}

The cultivation and improvement effect of college students' innovation ability is affected by various factors, and this ability is too complex to be evaluated accurately. For this, the authors attempt to propose an extension model suitable for evaluating the cultivation and improvement of the college students' innovation ability. This paper firstly defines the essential issues about the cultivation and improvement of the said ability, and discusses about the selection of relevant indicators. Then, based on extension theory, an evaluation model was established for the cultivation and improvement 
of the said ability, the workflow of model implementation was explained, and the corresponding evaluation algorithm was designed in details. Finally, the proposed model and algorithm were proved operable through case analysis. It's expected to provide a new perspective for the effective evaluation of the cultivation and improvement of college students' innovation ability.

\section{$7 \quad$ Acknowledgement}

This work is support by "13th Five-Year" education reform project for higher education in Zhejiang Province (No. jg20190911).

\section{References}

[1] Petti, C., Tang, Y., Margherita, A. (2019). Technological innovation vs technological backwardness patterns in latecomer firms: An absorptive capacity perspective. Journal of Engineering and Technology Management, 51, 10-20. https://doi.org/10.1016/j.jengtec man.2019.02.002

[2] Tang, Z., Liu, L., Li, X.H., Shi, C.B., Zhang, N., Zhu, Z.J., Bi, J. (2019). Evaluation on the eco-innovation level of the tourism industry in Heilongjiang Province, China: From the perspective of dynamic evolution and spatial difference. International Journal of Sustainable Development and Planning, 14(3), 202-215. https://doi.org/10.2495/SDP-V14$\underline{\mathrm{N} 3-202-215}$

[3] Krušinskas, R., Benetyte, R. (2015). Management problems of investment in technological innovation, using artificial neural network. Procedia-Social and Behavioral Sciences, 213, 442-447. https://doi.org/10.1016/j.sbspro.2015.11.431

[4] Cardinale, T., Sposato, C., A. Feo, P., Fazio, D. (2018). Clay and fibers: Energy efficiency in buildings between tradition and innovation. Mathematical Modelling of Engineering Problems, 5(3), 183-189. https://doi.org/10.18280/mmep.050308

[5] Bongiovanni, I. (2019). The least secure places in the universe? A systematic literature review on information security management in higher education. Computers \& Security, 86, 350-357. https://doi.org/10.1016/j.cose.2019.07.003

[6] Osman, A.S.A., Faizal Khan, Z. (2019). Novel methodology for arbitration of talented students using an electronic system: A higher education perspective, International Journal of Emerging Technologies in Learning, 14(21), 250-257. https://doi.org/10.3991/ijet.v14i21. $\underline{10916}$

[7] Jackson, N. C. (2019). Managing for competency with innovation change in higher education: Examining the pitfalls and pivots of digital transformation. Business Horizons, 62(6), 761-772. https://doi.org/10.1016/j.bushor.2019.08.002

[8] Gao, R.Y., Zhang, H.R. (2017). College Students' scientific and technological innovation and cultivation of scientific research ability. Experimental Technology and Management, 34(6), 180-182, 186. https://doi.org/10.16791/j.cnki.sjg.2017.06.045

[9] Zong, K., Zhong, L.B., Liu, Q.Z. (2017). The construction of evaluation index system of College Students' scientific and technological innovation quality. China Management Informa ionization, 20(15), 231-233. https://doi.org/10.3969/j.issn.1673-0194.2017.15.101 
[10] Li, W.H., Chen, H.L., Chen, Z.N. (2016). Model construction and development strategy of college students' science and technology innovation ability system. Science \& Technology and Economy, 29(4), 76-80. https://doi.org/10.14059/j.cnki.cn32-1276n.2016.04.016

[11] Pei, J.Y., Shan, P. (2019). A micro-expression recognition algorithm for students in classroom learning based on convolutional neural network. Traitement du Signal, 36(6), 557563. https://doi.org/10.18280/ts.360611

[12] Li, Y., Shi, D.L., Bu, F.J. (2019). Automatic recognition of rock images based on convolutional neural network and discrete cosine transform. Traitement du Signal, 36(5), 463-469. https://doi.org/10.18280/ts.360512

[13] Zagrebina, S. A., Mokhov, V. G., Tsimbol, V. I. (2019). Electrical energy consumption prediction is based on the recurrent neural network. Procedia Computer Science, 150, 340346. https://doi.org/10.1016/j.procs.2019.02.061

[14] Scarselli, F., Tsoi, A. C., Hagenbuchner, M. (2018). The Vapnik-Chervonenkis dimension of graph and recursive neural networks. Neural Networks, 108, 248-259. https://doi. org/10.1016/j.neunet.2018.08.010

[15] Tseng, H. E., Chang, C. C., Lee, S. C., Huang, Y. M. (2018). A Block-based genetic algorithm for disassembly sequence planning. Expert Systems with Applications, 96, 492505. https://doi.org/10.1016/j.eswa.2017.11.004

[16] Verotti, M., Di Giamberardino, P., Belfiore, N. P., Giannini, O. (2019). A genetic algorithm-based method for the mechanical characterization of biosamples using a MEMS microgripper: Numerical simulations. Journal of the mechanical behavior of biomedical materials, 96, 88-95. https://doi.org/10.1016/j.jmbbm.2019.04.023

[17] Bezuglov, A., Comert, G. (2016). Short-term freeway traffic parameter prediction: Application of grey system theory models. Expert Systems with Applications, 62, 284-292. https://doi.org/10.1016/j.eswa.2016.06.032

[18] Lee, C., Lee, J. W., Ryu, S. G., Oh, J. H. (2019). Optimum design of a large area, flexure based $\mathrm{XY} \theta$ mask alignment stage for a 12-inch wafer using grey relation analysis. Robotics and Computer-Integrated Manufacturing, 58, 109-119. https://doi.org/10.1016/ j.rcim.2019.02.005

[19] de Gusmão, A. P. H., Silva, M. M., Poleto, T., e Silva, L. C., Costa, A. P. C. S. (2018). Cybersecurity risk analysis model using fault tree analysis and fuzzy decision theory. International Journal of Information Management, 43, 248-260. https://doi.org/10.1016/j.ij infomgt.2018.08.008

[20] Shariat, R., Roozbahani, A., Ebrahimian, A. (2019). Risk analysis of urban stormwater infrastructure systems using fuzzy spatial multi-criteria decision making. Science of the Total Environment, 647, 1468-1477. https://doi.org/10.1016/j.scitotenv.2018.08.074.

[21] Chiramdasu, R. (2019). Extended statistical analysis on multimedia concealed data detections. Ingénierie des Systèmes d'Information, 24(2), 161-165. https://doi.org/10.182 $\underline{\text { 80/isi.240205 }}$

[22] Chao, K. H. (2014). An extension theory-based maximum power tracker using a particle swarm optimization algorithm. Energy conversion and management, 86, 435-442. https:// doi.org/10.1016/j.enconman.2014.05.018

[23] Abulkasim, H., Farouk, A., Alsuqaih, H., Hamdan, W., Hamad, S., Ghose, S. (2018). Improving the security of quantum key agreement protocols with single photon in both polarization and spatial-mode degrees of freedom. Quantum Information Processing, 17(11), 316. https://doi.org/10.1007/s11128-018-2091-7

[24] Seyedmohammadi, J., Sarmadian, F., Jafarzadeh, A. A., McDowell, R. W. (2019). Development of a model using matter element, AHP and GIS techniques to assess the 
suitability of land for agriculture. Geoderma, 352, 80-95. https://doi.org/10.1016/j.geoder ma.2019.05.046

[25] Chen, R. M., Yang, S. C., Wang, C. M. (2017). MRI brain tissue classification using unsupervised optimized extenics-based methods. Computers \& Electrical Engineering, 58, 489-501. https://doi.org/10.1016/j.compeleceng.2017.01.018

[26] Vladareanu, L., Vladareanu, V., Yu, H., Mitroi, D., Ciocîrlan, A. C. (2019). Intelligent Control Interfaces Using Extenics Multidimensional Theory Applied on VIPRO Platforms for Developing the IT INDUSTRY 4.0 Concept. IFAC-PapersOnLine, 52(13), 922-927. https://doi.org/10.1016/j.ifacol.2019.11.312.

[27] Wang, W.X. (2019). Site selection of fire stations in cities based on geographic information system (GIS) and fuzzy analytic hierarchy process (FAHP). Ingénierie des Systèmes d'Information, 24(6), 619-626. https://doi.org/10.18280/isi.240609

[28] Vardi, M., Neyestani, M., Ghorbanian, A. (2019). Supplier selection and order allocation problem modeling with the aim of comparing incremental discounts versus wholesale discounts by using GA and NSGA algorithms. Journal Européen des Systèmes Automatisés, 52(1), 23-34. https://doi.org/10.18280/jesa.520104

\section{Authors}

Kechuang Wang received the M.S. degrees from the Southwest University in 2009. He is an Associate Professor of Zhejiang Dongfang Polytechnic, Wenzhou 325000, China. Email: wangkechuang@126.com

Chuankui Yan received the M.S. degrees from the South China University of Technology in 2007 and the Ph.D. degree in control engineering from Institute for Cognitive Neurodynamics of the East China University of Science and Technology, in 2012. He is an Associate Professor of College of Mathematics and physics, Wenzhou University, Wenzhou 325035, China. E-mail: yanchuankui@163.com

Article submitted 2020-07-01. Resubmitted 2020-08-14. Final acceptance 2020-08-15. Final version published as submitted by the authors. 